\title{
Crescimento de mudas de orégano submetidas a doses e frequências de aplicação de Ácido L-glutâmico em sistema orgânico
}

\author{
BETTONI, M.B. ${ }^{1 *}$; FABBRIN, E.G. dos S. ${ }^{1}$; PROCOPIUK, M. ${ }^{1}$; MÓGOR, A.F. ${ }^{1}$ \\ 1 Universidade Federal do Paraná - Setor de Ciências Agrárias- Departamento de Fitotecnia e Fitossanitarismo, \\ Rua dos Funcionários, 1540, Juvevê, 80.035-050 Curitiba-PR. E-mail: *m2bettoni@gmail.com, eliseufabbrin@ \\ yahoo.com.br, prokopiuk@live.com, atila.mogor@ufpr.br.
}

\begin{abstract}
RESUMO: O presente trabalho teve por objetivo identificar o efeito de diferentes doses e frequências de aplicação do biofertilizante aminoácido Ácido L-glutâmico em mudas de orégano produzidas em sistema orgânico, quantificando seu crescimento. Os tratamentos compostos por 2 doses $\left(0,4\right.$ e $\left.0,8 \mathrm{~mL} \mathrm{~L}^{-1}\right)$ de Ácido L-glutâmico a 30\%, e testemunha com água, foram aplicados via foliar em intervalos regulares de 7 e 14 dias, por 28 dias (fatorial $3 \times 2$, com 4 e 2 aplicações, respectivamente), em delineamento inteiramente casualizado com 4 repetições. Aos 62 dias após a semeadura foi realizada a coleta de 8 plantas centrais por repetição para avaliação de características biométricas da parte aérea e das raízes. O experimento demonstrou que o biofertilizante aminoácido ácido L-glutâmico influenciou as características avaliadas. A dose de $0,8 \mathrm{~mL} \mathrm{~L}^{-1}$, aplicada com intervalo de 14 dias, promoveu maior crescimento das mudas de orégano.
\end{abstract}

Palavras-chave: Aminoácido, biofertilizante, planta condimentar, Origanum vulgare L

ABSTRACT: Growth of oregano (Origanum vulgare L.)seedlings in different levels and frequencies of foliar application of the I-glutamic acid in the organic system. The aim of this study was to identify the effect of the different levelsand frequencies of foliar application of the biofertilizer L-glutamic acid in oregano seedlings produced in the organic system, quantifying their growth. The treatments were arranged in a completely randomized design with four replications in a $3 \times 2$ factorialarrangement, consisting of two doses $\left(0.4\right.$ and $\left.0.8 \mathrm{ml} \mathrm{L}^{-1}\right)$ of a compound with $30 \% \mathrm{~L}$-glutamic acid and a control, under a frequency of two applications, with a total of 4 applications for the 7-day frequency, and 2 applications for the 14-day frequency. At the 62nd day after sowing, eight plants were collected per replication for measuring biometric characteristics of shoots and roots. The biofertilizer L-glutamic acid affected the evaluated characteristics, and the dose of $0.8 \mathrm{ml} \mathrm{L}^{-1}$ (applied with a 14-day interval), promoted greater seedling growth of oregano.

Keywords: Aminoacid, Aminoacid, biofertilizer, spice plant, Origanum vulgare L

\section{INTRODUÇÃO}

O orégano, Origanum vulgare L. (Lamiaceae), é uma planta herbácea, rasteira, de folhas verdes, pequenas e aromáticas, sendo considerado um dos condimentos mais tradicionais da culinária brasileira. Embora sua utilização ocorra em maior quantidade nas indústrias de alimentos, o orégano também é utilizado em indústrias farmacêuticas em razão de suas propriedades terapêuticas (Souza \& Standford, 2005). Mesmo havendo grande demanda deste condimento, o suprimento da demanda brasileira, acontece principalmente por meio de importação (Castro \&
Ramos, 2003).

O cultivo de plantas condimentares e aromáticas de acordo com parâmetros do sistema orgânico vem se sobressaindo como uma das principais atividades da agricultura familiar. Nesta atividade, a produção de mudas com qualidade, baixo custo, homogêneas e vigorosas é fundamental quanto se tem em vista o cultivo comercial (Paiva et al., 2011). Ao contrário, mudas de baixa qualidade poderão comprometer o estabelecimento da cultura a campo, bem como sua produtividade final. Neste contexto, a adoção de técnicas alternativas se 
faz importante para a obtenção de mudas de alta qualidade e com rentabilidade razoável para o produtor (Filgueira, 2003).

Dentre as alternativas de cultivo, o sistema orgânico se caracteriza por não permitir a utilização de produtos químicos sintéticos (Linhares et al., 2009), tais como os fertilizantes de alta solubilidade. Alternativamente, podem ser utilizados aminoácidos com estabilização fermentativa, por agirem como biofertilizantes e como estimuladores do crescimento vegetal (Albuquerque Neto \& Albuquerque, 2008).

Alguns trabalhos demonstram os efeitos atribuídos aos aminoácidos (Deleito et al., 2005; Mógor et al., 2008; Olinick et al., 2011), dentre os quais, destaca-se o aminoácido Ácido L-glutâmico, obtido através da fermentação do melaço da cana-de-açúcar pela bactéria Corynebacterium glutamicum. A utilização de tais substâncias em complementação ou substituição a fertilizantes convencionais ganha crescente importância, tanto sob o ponto de vista econômico, quanto ecológico (Piccoli et al., 2009).

O objetivo deste trabalho foi avaliar o efeito de doses e frequências de aplicação do biofertilizante aminoácido Ácido L-glutâmico no crescimento de mudas de orégano em sistema orgânico.

\section{MATERIAL E MÉTODO}

O experimento foi conduzido em casa de vegetação, na área experimental de olericultura orgânica, do Centro de Estações Experimentais do Canguiri - UFPR (Latitude $25^{\circ} 25^{\prime}$, Longitude $49^{\circ}$ 06'; 920 m de altitude). A exsicata de orégano está depositada no herbário Esal sob registro n 22.156.

As mudas de Origanum vulgare L. foram obtidas a partir de sementes provenientes do Viveiro Flor e Cultura, localizado em Florianópolis-SC. A semeadura foi realizada no dia 16/12/2011 em bandejas plásticas com 200 células, colocandose 2 sementes por célula, com raleio realizado 10 dias após a germinação, mantendo-se uma planta por célula. As células foram preenchidas com os substratos Pró Vaso ${ }^{\circledR}$ (composto de cama de aviário) associado a casca de pinus compostada, na proporção de 1:1,5, respectivamente. As bandejas foram mantidas em casa de vegetação com irrigação por micro-aspersão temporizada com intervalos de duas horas, durante todo período experimental.

Os tratamentos foram dispostos em delineamento inteiramente casualizado com 4 repetições, em esquema fatorial $3 \times 2$ (doses e frequências, respectivamente), sendo cada parcela constituída por 50 células, as quais foram isoladas, cortando-se as bandejas. Os tratamentos foram compostos de duas doses do biofertilizante AG- $30^{\circledR}$
(Microquímica Indústrias Químicas Ltda - Monte MorSP), 0,4 e 0,8 $\mathrm{ml} \mathrm{L}^{-1}$, composto por aminoácido Ácido L-glutâmico a 30\%, e a testemunha, com aplicação de água, em dois intervalos de aplicação: 7 e 14 dias, através de pulverização foliar. As aplicações iniciaram-se aos 34 dias após a semeadura (DAS), sendo que no intervalo de 7 dias foram efetuadas 4 aplicações do ácido, aos 34, 41, 48 e 55 DAS, e no intervalo de 14 dias, apenas duas aplicações, aos 34 e 48 DAS.

Para a aplicação foliar do biofertilizante foi utilizado um pulverizador pressurizado com $\mathrm{CO}_{2}$, com pressão constante (45 lib pol- ${ }^{2}$ ) e volume de calda equivalente a $15 \mathrm{~L} \mathrm{ha}^{-1}$, sendo as parcelas removidas da casa-de-vegetação, na ocasião da aplicação, para que não houvesse contaminação.

Aos 62 DAS foram coletadas, por repetição, oito plantas centrais para a avaliação das seguintes características: número de folhas (NF), altura da parte aérea (APA), teor relativo de clorofila (TRC), área foliar ( $\mathrm{AF}$ ), volume foliar (VF), massa fresca da parte aérea (MFPA), massa seca da parte aérea (MSPA), massa fresca de raiz (MFR), massa seca de raiz (MSR), volume radicular (VR), área radicular (AR), comprimento total de raízes (CTR), e porcentagem de raízes finas $(R F)(0-1 \mathrm{~mm})$, médias (RM) (1-2 mm) e grossas (RG) (2-3 mm).

Para identificar a APA foi utilizada régua graduada. O TRC foi determinado pelo clorofilômetro manual N-Tester ${ }^{\circledR}$ (Yara, 2000). Para a obtenção da AF, VF e VR, AR, CTR RF, RM e RG as amostras foram analisadas por meio do programa computacional WinRhizo ${ }^{\circledR}$, acoplado a um Scanner LA1600 (Règent Instruments Inc.- Canadá). As folhas foram destacadas e pressionadas para que se pudesse efetuar a leitura dos parâmetros. As raízes, por sua vez, foram imersas em água para facilitar sua separação.

A homogeneidade das variâncias foi avaliada pelo teste de Barttlet e quando homogêneas, prosseguiu-se com a ANOVA (Analysis of Variance), seguida pelo teste de regressão. Os dados foram processados no software estatístico Assistat 7.5.

\section{RESULTADO E DISCUSSÃO}

Os resultados do NF, APA, TRC e AF são apresentados na Figura 1.

O maior NF foi obtido na dose $0,8 \mathrm{ml} \mathrm{L-1}$ de ácido L-glutâmico (Figura 1a), aplicada com intervalo de 14 dias, com média de 73,5 folhas, indicando que o produto promoveu a emissão foliar na maior dose e menor frequência.

De forma similar, a APA apresentou o maior valor médio na menor frequência (14 dias) e dose de $0,8 \mathrm{ml} \mathrm{L}^{-1}$ (Figura 1b), entretanto, sem diferir da frequência de 7 dias, na dose $0,4 \mathrm{ml} \mathrm{L-}{ }^{1}$, 

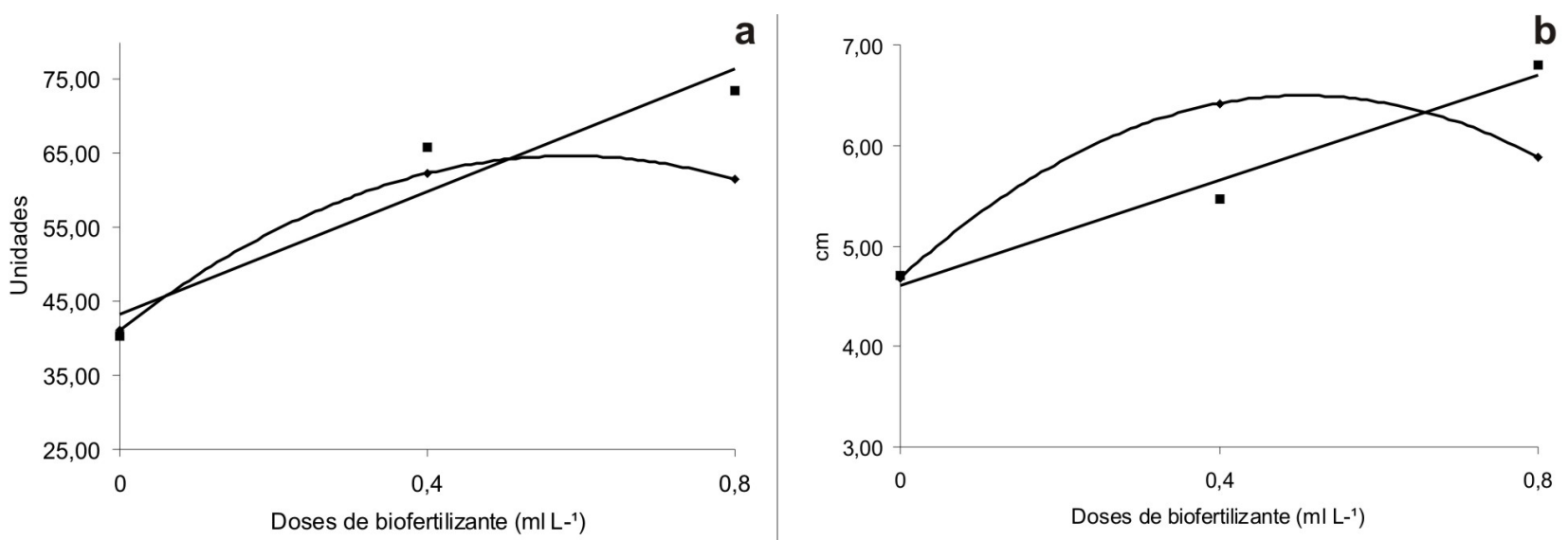

- NF 7 dias: $y=-68,75 x^{2}+80,417 x+41,167+R^{2}=1$

- NF 14 dias: $y=41,458 x+43,306 \_R^{2 \star \star}=0,9121$

- APA 7 dias: $y=-7,0833 x^{2}+7,1667 x+4,6833 \_R^{2 * *}=1$

- APA 14 dias: $y=2,625 x+4,6056 \_R 2^{* *}=0,9763$

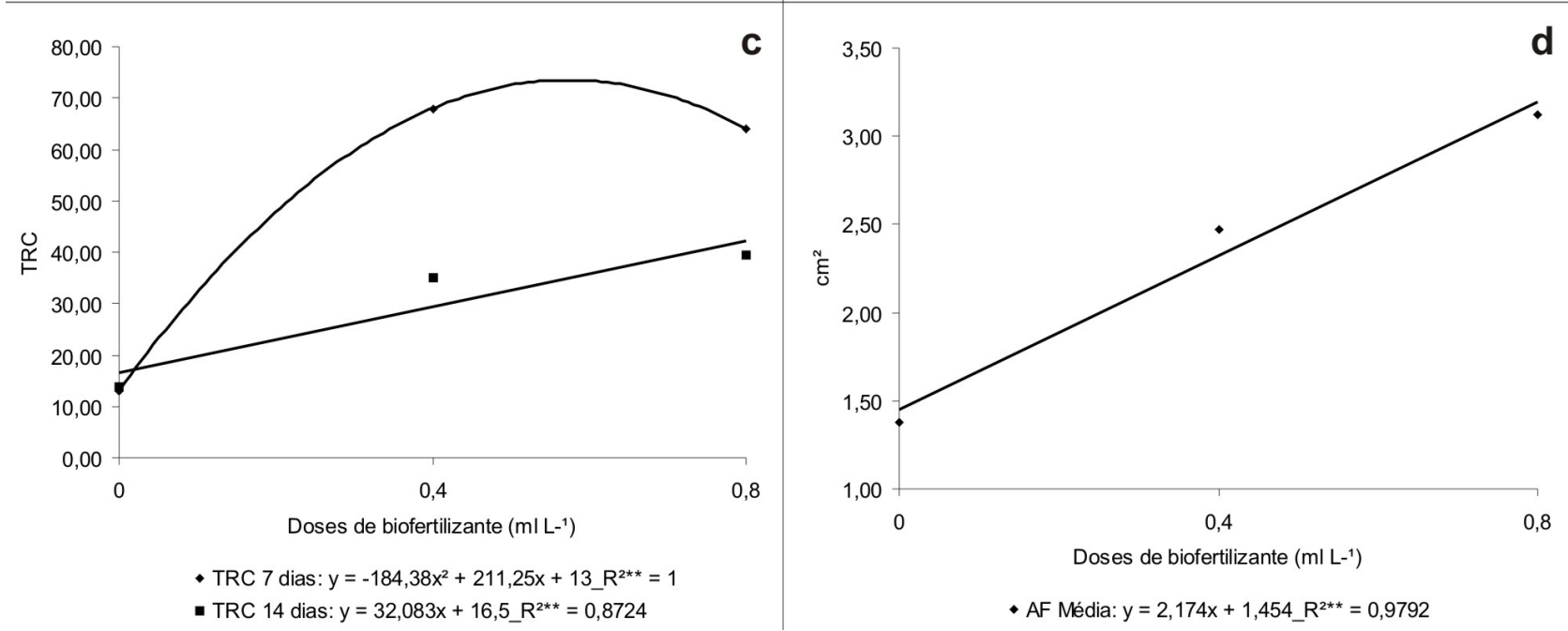

FIGURA 1. a) Número de folhas (NF), b) altura da parte aérea (APA), c) teor relativo de clorofila (TRC) e d) área foliar (AF) de mudas de orégano em função de diferentes doses e frequências de aplicação (a cada 7 dias (7D) e a cada 14 dias (14D)) do biofertilizante ácido L-glutâmico. Curitiba, 2012.

indicando que ao aumentar frequência de aplicações é possível reduzir a dose do produto.

Embora o TRC, em todos os tratamentos, tenha sido superior ao da testemunha, os maiores valores foram observados na maior frequência em ambas as doses (Figura 1c). Resultados semelhantes também foram observados por Röder et al. (2011) em beterraba e por Olinick et al. (2011b) em mudas repolho. Esse efeito pode estar relacionado a disponibilidade do aminoácido em um menor intervalo de tempo, já que atua como precursor primário na biossíntese da clorofila (Taiz \& Zeiger, 2006).

A variável $A F$ (Figura 1c), assim como as variáveis VF, MFPA e MSPA (Figura 2) não apresentaram interação significativa entre doses e frequências de aplicação. Entretanto verificou-se que na dose $0,8 \mathrm{ml} \mathrm{L-}^{-1}$, os valores médios de AF
(Figura 1c) e VF (Figura 2a) foram superiores aos da testemunha, como pode ser observado na Figura 3 , em conseqüência do efeito do aminoácido no crescimento das plantas, como já identificado nas variáveis NF e APA (Figura 1).

Como reflexo do maior crescimento, a MFPA e MSPA também apresentaram maiores valores médios com a aplicação do produto em ambas as doses, quando comparadas a testemunha. Tais resultados podem ser atribuídos à expansão foliar em virtude da absorção do aminoácido ácido L-glutâmico, que convertido a glutamato, pode atuar nos mecanismos de crescimento relacionados ao metabolismo do N (Yu et al., 2010).

Os dados relativos ao efeito dos tratamentos no crescimento do sistema radicular são apresentados nas Figuras 4 e 5 . Os valores médios da MFR indicaram o efeito da dose $0,8 \mathrm{ml}$ 


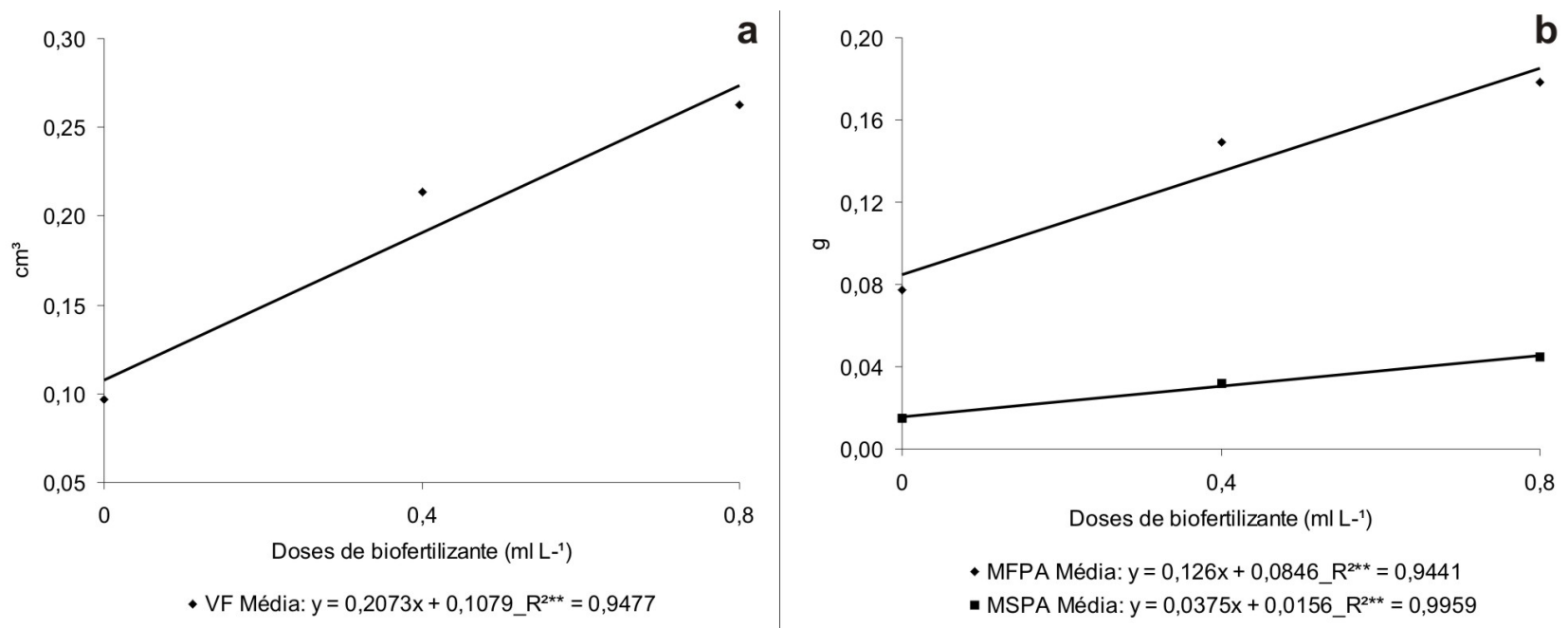

FIGURA 2. a) Volume foliar (VF), b) massa fresca da parte aérea (MFPA) e massa seca da parte aérea (MSPA) de mudas de orégano em função de diferentes doses e freqüências de aplicação (a cada 7 dias (7D) e a cada 14 dias (14D)) do biofertilizante ácido L-glutâmico. Curitiba, 2012.

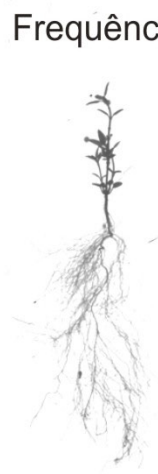

$0,0 \mathrm{ml} \mathrm{L}^{-1}$

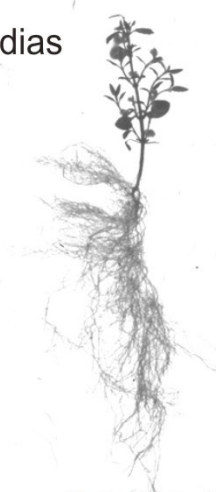

$0,4 \mathrm{ml} \mathrm{L}^{-1}$

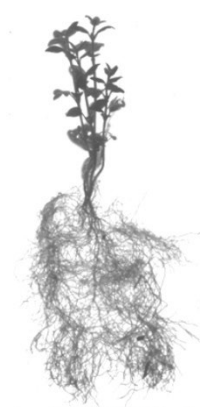

$0,8 \mathrm{ml} \mathrm{L}^{-1}$

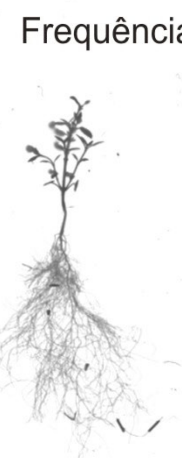

$0,0 \mathrm{ml} \mathrm{L-1}$

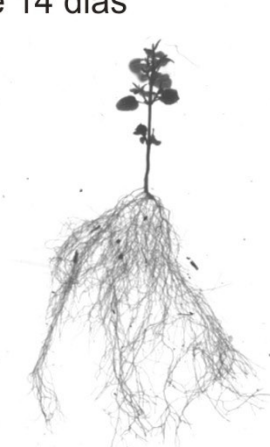

$0,4 \mathrm{ml} \mathrm{L}^{-1}$

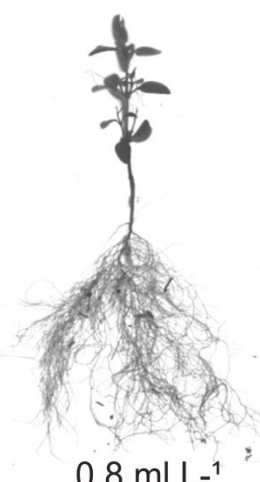

$0,8 \mathrm{ml} \mathrm{L-1}$

FIGURA 3- Imagem obtida por meio do programa computacional WinRhizo ${ }^{\circledR}$, da parte aérea e das raízes de mudas de orégano em função de diferentes doses e frequências de aplicação do ácido L-glutâmico. Curitiba, 2012.

L-1 no intervalo de 14 dias, com o maior valor, sem diferir dos tratamentos realizados no intervalo de 7 dias (Figura 4a).

O efeito dos tratamentos no acúmulo de biomassa radicular fica bem demonstrado pela variável MSR (Figura 4b), cujos valores foram superiores aos da testemunha em ambas as frequências e doses de aplicação.

Como conseqüência do maior acúmulo de massa seca (MSR), o mesmo comportamento foi observado com relação ao VR (Figura 4c). Tais resultados estão de acordo com Olinick et al. (2011b), que observaram o aumento das massas seca e volume de raízes de mudas de repolho em função de tratamentos com o biofertilizante ácido L-glutâmico.

Apesar de não ter ocorrido interação entre os fatores, como apresentado na Figura $4 \mathrm{~d}$, com a análise isolada dos fatores, a menor dose com menor intervalo de aplicação e a maior dose $(0,8$ $\mathrm{ml} \mathrm{L-}{ }^{1}$ ) independente do intervalo, promoveram o aumento da AR.

Ao analisar a distribuição das classes do diâmetro radicular, verifica-se que cerca de $90 \%$ da biomassa das raízes concentrou-se na classe de raízes finas (diâmetro $\leq 1,0 \mathrm{~mm}$ ), independentemente dos tratamentos. Isto reflete a condição de limitação do crescimento radicular relacionada à produção de mudas em bandejas, que resulta em intensa proliferação de eixos finos (Zonta et al., 2006).

Ainda assim, verifica-se que os tratamentos promoveram o aumento da proporção de RM (Figura 5c) e RG (Figura 5d) em detrimento das RF (Figura $5 b)$. Portanto, as alterações identificadas na MFR, MSR, VR e AR, em função dos tratamentos (Figura 4), estão relacionados ao espessamento do sistema radicular, o que pode ser explicado pela translocação 

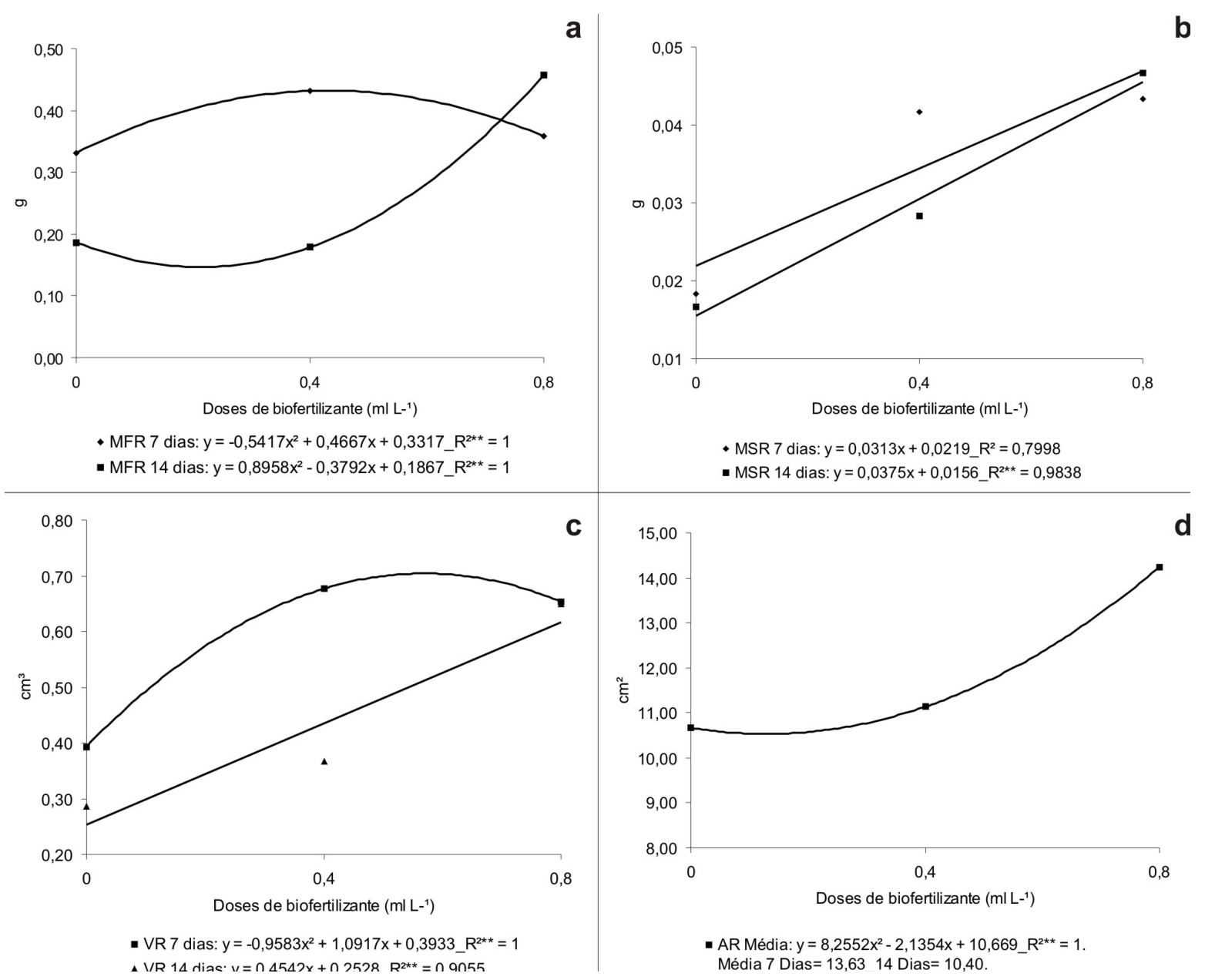

FIGURA 4. a) Massa fresca radicular (MFR), b) massa seca radicular (MSR), c) volume radicular (VR) e d) área radicular (AR) de mudas de orégano em função de diferentes doses e frequências de aplicação (a cada 7 dias (7D) e a cada 14 dias (14D)) do biofertilizante do ácido L-glutâmico. Curitiba, 2012.

e acúmulo de fotoassimilados (Taiz \& Zieger, 2006).

\section{CONCLUSÃO}

No experimento ficou evidenciado que o efeito do biofertilizante aminoácido ácido L-glutâmico, quando aplicado na dose de $0,8 \mathrm{ml} \mathrm{L-1}$, aos 34 e 48 dias após a semeadura, promovendo maior crescimento de mudas de orégano no sistema orgânico.

\section{REFERÊNCIA}

ALBUQUERQUE, N.A.A.R.de; ALBUQUERQUE, T.C.S.de. Cultivo da couve em substrato fertirrigado com aplicações de organominerais. In: FERTBIO: REUNIÃO BRASILEIRA DE FERTILIDADE DO SOLO E NUTRIÇÃO DE PLANTAS, 28, 2008, Londrina-PR.
Anais... Londrina-PR: Sociedade Brasileira de Ciência do Solo, 2008.

CASTRO, L.O.; RAMOS, R.L.D. Descrição botânica, cultivo e uso de Origanum majorana L., manjerona e de Origanum vulgare L., orégano (LAMIACEAE). Porto Alegre: FEPAGRO, 2003. (Circular Técnica, 22).

CRUZ, P.; BOVAL, M. Effect of nitrogen on some morphogenetical traits of temperate and tropical perennial forage grasses. In: SIMPÓSIO INTERNACIONAL GRASSLAND ECOPHYSIOLOGY AND GRAZING ECOLOGY,1999, Curitiba-PR. Anais... Curitiba-PR: Universidade Federal do Paraná, 1999. p. 134-150.

DELEITO, C.S.R. et al. Ação do biofertilizante Agrobio sobre a mancha-bacteriana e desenvolvimento de mudas de pimentão. Horticultura Brasileira, BrasíliaDF, v. 23, n. 1, p. 117-122, 2005.

FILGUEIRA, F.A.R. Novo manual de agrotecnologia moderna na produção e comercialização de hortaliças. Viçosa: UFV, 2003.

KING, B. J. et al. Feedback regulation of nitrate influx in barley roots by nitrate, nitrite, and ammonium. Plant Physiology, Derwood- USA, v. 102, p. 1279-1286, 1993. 

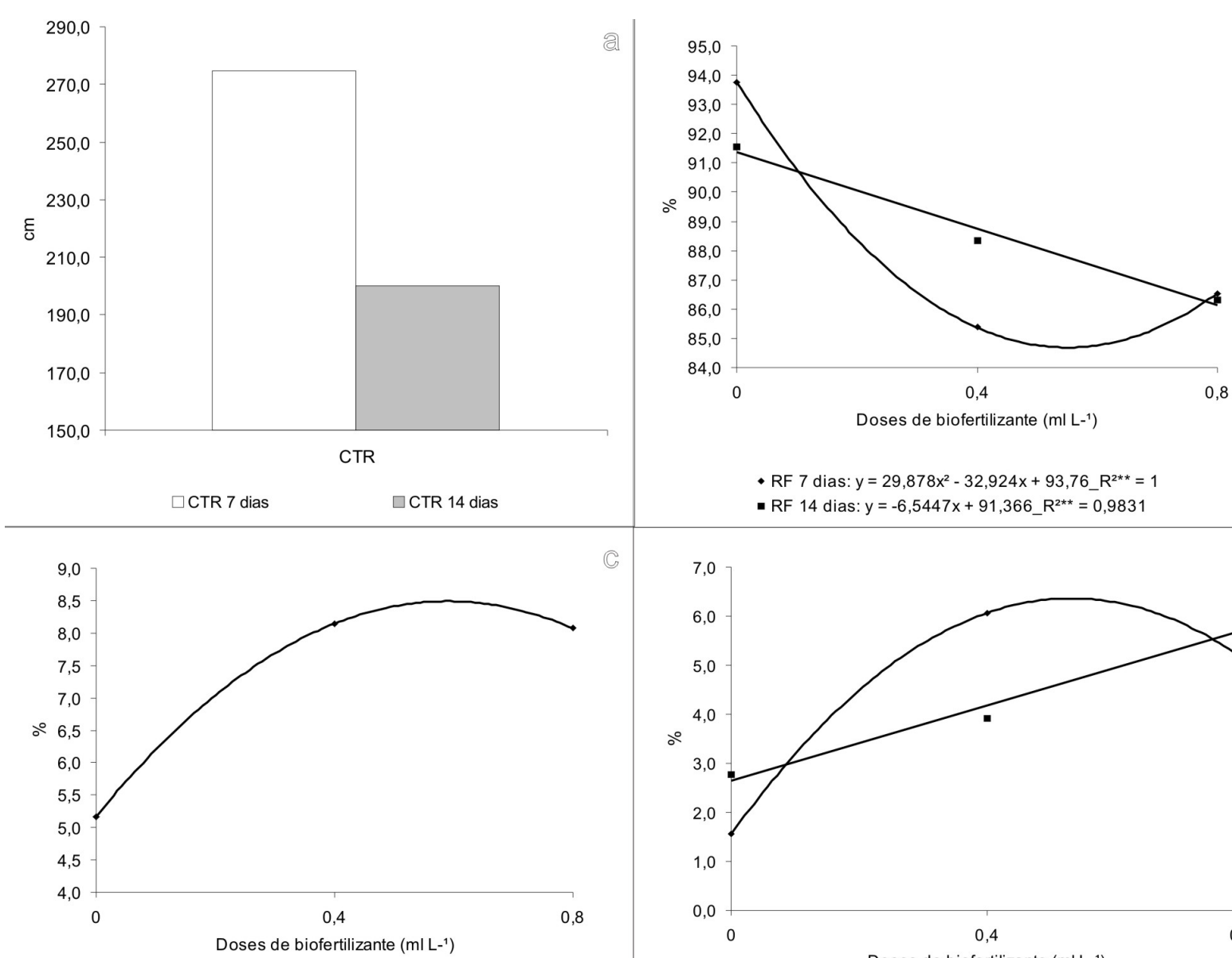

- RM Média: $y=-9,5279 x^{2}+11,245 x+5,173 \_R^{2 \star \star}=1$

- RF 7 dias: $y=29,878 x^{2}-32,924 x+93,76 R^{2 \star \star}=1$ - RF 14 dias: $y=-6,5447 x+91,366 \_R^{2 \star \star}=0,9831$

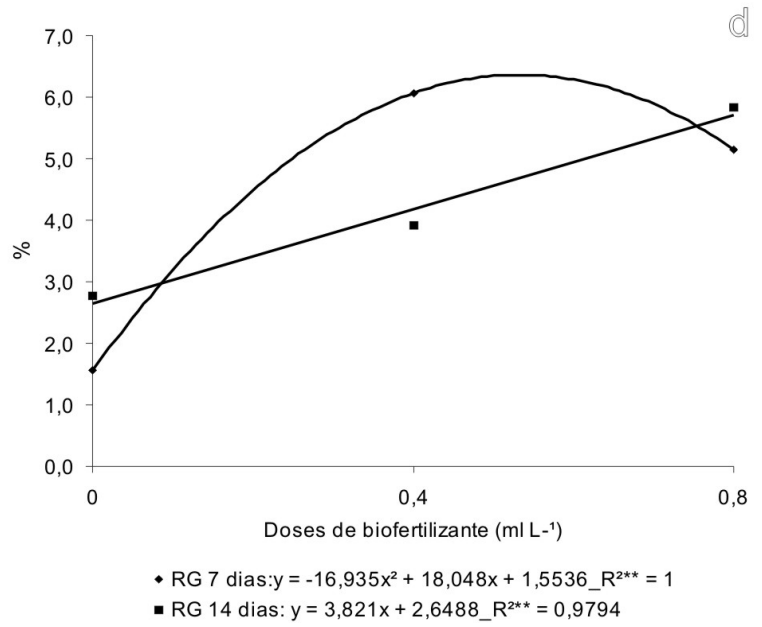

FIGURA 5. a) Comprimento total de raízes (CTR), b) raízes finas (RF\%), c) raízes médias (RM\%) e d) raízes grossas (RF\%) de mudas de orégano em função de diferentes doses e frequências de aplicação (a cada 7 dias (7D) e a cada 14 dias (14D)) do biofertilizante do ácido L-glutâmico. Curitiba, 2012.

LINHARES, P.C.F. et al. Produção da rúcula em função de diferentes tempos de decomposição da malva veludo. Revista Caatinga, Mossoró, v. 22, n. 2, p. 50-54, 2009. MÓGOR, A.F. et al. Aplicação foliar de extrato de alga, ácido I-glutâmico e cálcio em feijoeiro. Scientia Agraria, Curitiba, v. 9, n. 4, p. 431-437, 2008.

OLINIK, J.R. et al. Frequência de aplicação de ácido L-glutâmico a $30 \%$ na qualidade de mudas de repolho. Horticultura Brasileira, Brasília- DF, n. 29, p. 42614264, 2011a.

OLINIK, J.R et al. Desenvolvimento de mudas de repolho em função da aplicação foliar de ácido L-glutâmico a $30 \%$. Horticultura Brasileira, Brasília- DF, v. 29, p. 4256-4260, 2011b.

PAIVA, E.D. et al. Composição do substrato para o desenvolvimento de mudas de manjericão (Ocimum basilicum L.). Revista Caatinga, Mossoró, v. 24, n. 4, p. 62-67, 2011.

PICOLLI, E.S. et al. Aplicação de produtos a base de aminoácido na cultura do trigo. Cultivando o Saber, Cascavel, v. 2, n. 4, p. 141-148, 2009.

RÉGENT INSTRUMENTS. Win/MacRHIZO V4. 1c Reference. Régent Instruments Inc., Québec, Canada. 1999. 51p.
RÖDER C. et al. Teor relativo de clorofila em beterraba submetido à aplicação foliar de AG $30^{\circledR}$, em sistema orgânico de produção. Horticultura Brasileira, Brasília- DF, v. 29, p. 4130-4134, 2011.

SOUZA, E.L.; STANFORD, T.L.M. Orégano (Origanum vulgare L. - Lamiace): uma especiaria com potencial fonte de compostos microbianos. Higiene Alimentar, São Paulo- SP, v. 19, n. 132, p. 40-45. 2005.

TAIZ, L.; ZIEGER, E. Plant Physiology. Sunderland: Sinaver Associates. $3^{a}$ Edição. Califórnia, 2006. 722p.

TISCHNER, R. Nitrate uptake and reduction in higher and lower plants. Plant, Cell and Environment, Estados Unidos, v. 23, p. 1005-1024, 2000.

YARA. How to use the $\mathbf{N}$-Tester. 2000. Disponível em: http://www.yarabrasil.com.br/fertilizer/tools_and_ services/index.aspx. Acesso em 15 set. 2011.

ZONTA, E. et al. O sistema radicular e suas interações com o ambiente edáfico, In.: Nutrição Mineral de Plantas. (Ed.) Fernandes, M. S., Sociedade Brasileira de Ciência do Solo, Viçosa, p. 7-52, 2006.

$\mathrm{YU}, \mathrm{C}$. et al. Changes in photosynthesis, fluorescence, and nitrogen metabolism $\mathrm{f}$ hawthorn (Crataegus pinnatifida) in response to exogenous glutamic acid. Photosynthetica, v. 3, n. 48, p. 339-347, 2010. 